\title{
Analyticity and Katz's New Intensionalism: or, If you Sever Sense from Reference, Analyticity is Cheap but Useless*
}

\author{
Jonathan Cohen ${ }^{\dagger}$
}

In the new metalanguage of semantics, it is possible to make statements about the relation of designation and about truth.... To me the usefulness of semantics for philosophy was so obvious that I believed no further arguments were required and it was sufficient to list a great number of customary concepts of a semantical nature ([Carnap, 1963], 60-62).

Jerry Katz has observed that much of twentieth century philosophy of language turns on the Fregean thesis that sense determines reference. For example, he suggests that this thesis underwrites the widespread understanding of 'analyticity' (what he calls "the standard view") as (necessary) truth in virtue of meaning alone. In addition, Katz argues that the Fregean thesis is a necessary premise in widely accepted arguments for externalist conclusions about the semantics of natural kind terms and semantic knowledge.

But, precisely because it plays a pivotal role in arguments for these widelyheld positions, Katz thinks the Fregean thesis is an error of tremendous import. He argues that rejecting the Fregean thesis not only corrects a misimpression about the relationship between sense and reference shared by almost all semanticists in the post-Fregean tradition, but also clears the way for a novel understanding of 'analyticity' not vulnerable to Quinean attacks, and allows for a "rationalist/internalist" conception of reference and semantic knowledge of the kind Putnam and Kripke have convinced many is unattainable. As Katz is at pains to emphasize, these consequences challenge directly some of the most widely- and dearly-held positions in philosophy of language. ${ }^{1}$ For these reasons, it seems that quite a lot hangs on the viability of Katz's proposal. Therefore, the question whether his program can be sustained is of considerable philosophical

\footnotetext{
*Forthcoming in Philosophy and Phenomenological Research.

${ }^{\dagger}$ Department of Philosophy, Rutgers University, joncohen@ruccs.rutgers.edu

${ }^{1}$ Moreover, whether Katz's internalist recasting of 'analyticity' is defensible will be of interest to theorists (including not only philosophers but also linguists and psychologists) attempting to explain the analyticity of sentences/thoughts solely in terms of what's inside the heads of competent speakers/thinkers. Many theories of lexical and conceptual meaning would satisfy this description, including meaning-postulate accounts in the tradition of [Carnap, 1956], (cf., [Partee, 1995], 328), inferential-role accounts (e.g., [Block, 1986], [Harman, 1982], [Rosch, 1978], [Smith and Medin, 1981]), and so-called theory-theory accounts (e.g., [Keil, 1987], [Carey, 1991], [Gopnik, 1988]).
} 
interest.

Unfortunately, I don't think Katz's program can succeed. In what follows I shall argue that, because he rejects the Fregean thesis, Katz ends up with an impoverished account of analyticity incapable of doing the work demanded of it by Katz (or anyone else). If this is right, then we have no reason to endorse Katz's idiosyncratic notions of sense and analyticity over their traditional Fregean competitors.

\section{Katz's Intensional Semantics}

\subsection{The Referential Autonomy of Sense}

Katz's rejection of Fregean semantics turns on providing a definition of 'sense' which makes no contact with reference. This definition is

(D) The sense of an expression is that aspect of its grammatical structure which is responsible for its sense properties and relations, i.e., having a sense (meaningfulness), sameness of sense (synonymy), opposition of sense (antonymy) and so on ([Katz, 1997], 8; cf., [Katz, 1972], 1-12).

What is crucially absent from the notion of sense given in (D), of course, is the traditional (Fregean) idea that the sense of an expression determines that expression's reference. Indeed, Katz insists that a referentially autonomous theory of sense based on (D) cannot be connected with reference in the usual way:

the theory of sense cannot even express the principle that sense determines reference - or, for that matter, any other principle about the relation between sense and reference. A principle like (E) which states the conditions under which something is the referent of a term is inexpressible because the vocabulary of the theory contains no concepts from the theory of reference, not even referent. ([Katz, 1997], 8)

(E) The referent of a term is something that falls under its sense.

At this point we may ask why Katz is interested in a referentially autonomous theory of sense. Part of his reason is that he accepts well-known externalist arguments (cf., [Putnam, 1975], [Burge, 1979], and [Kripke, 1980]) for the claim that whatever determines reference can't be in the head. On the other hand, Katz wants to hold that what is in the head is sufficient to determine an expression's sense-properties. The obvious way to reconcile these claims, suggests Katz, is simply to deny that sense determines reference, thereby making the externalist conclusion that the determiner of reference isn't in the head wholly irrelevant to the question whether sense is in the head. This clears the way for Katz to defend a "new intensionalism" which locates sense safely within the head. 
Katz has further arguments to show that sense ought not to be taken to determine reference. He distinguishes between "token-reference" (the reference of a dated token utterance of a linguistic expression) and "type-reference" (the reference of the tokens of a given linguistic type), and claims that the sense of an expression can determine neither its token- nor type-reference. ${ }^{2}$ First, he thinks, "non-literal uses of language in and of themselves show that the sense of an expression type does not determine the reference of its tokens" (9). Moreover, Katz thinks, the same conclusion is proven by cases inspired by [Donnellan, 1966]. For example, he claims, the subject NP of a particular token of

(4) The man in the corner drinking champagne is tall,

can refer to a woman in the corner drinking water, ${ }^{3}$ even though "the sense of the subject of the token ... is the man in the corner drinking champagne" (9). ${ }^{4}$

On the side of type-reference, Katz claims that rejecting the claim that sense determines reference is advisable because of the difficulty of assigning references (/extensions) to expression types including relative adjectives (it can be true both that $x$ is a big animal and that $x$ is not a big elephant; should $x$ be put in the extension of 'big'?) which nonetheless seem to have determinate sense-properties ('big' and 'small' are antonymous, 'big' and 'large' are synonymous). The point, then, is that such expressions can plausibly be held to have senses (whence their sense-properties), but cannot be assigned determinate type-references, so they are counterexamples to the claim that sense determines type-reference.

\subsection{Analyticity and the New Intensionalism}

According to the theory of sense founded on (D), the sense properties of an expression are determined by its sense, but its referential properties (such as its

\footnotetext{
${ }^{2}$ Katz thinks this is the lesson of Wittgenstein's claim that "we are not equipped with rules for every possible application of [a word]" ([Wittgenstein, 1953], §80).

${ }^{3}$ An anonymous referee has pointed out that while Katz presupposes here that definite descriptions are referring expressions, the widely accepted Russellian analysis has it that definite descriptions are quantifier expressions, and therefore don't refer at all. Presumably, though, Katz's point could be assimilated to a quantificational analysis; the claim then would be that (4) can sometimes mean something like $((\exists x)(x$ is a woman in the corner drinking water $) \&(y)(y$ is a woman in the corner drinking water $\supset x=y) \&(x$ is tall $)$ ) rather than something like $((\exists x)(x$ is a man in the corner drinking champagne)\& $(y)(y$ is a man in the corner drinking champagne $\supset x=y) \&(x$ is tall $))$. Analogous modifications of the claim would allow Katz to maintain that some (other) tokens of (4) might be used to talk about a man in the corner drinking gin, a child across the room drinking lemonade, etc. For purposes of discussion, I'll put this point aside and join Katz in treating definite descriptions as referring expressions, if only for ease of expression.

${ }^{4}$ I'm using italics for senses (although Katz uses single quotation marks), and reserving single quotation marks for mentioning expressions. Marking the distinction between expressions and senses with this device seems advisable insofar as Katz thinks senses are (not phrases, but) structured mental representations (see, e.g., [Katz and Fodor, 1963] or [Katz, 1972]). Thus, here and in what follows, I'll freely modify quotations from Katz to conform with the distinction I have suggested. Notice also, in this connection, that Katz understands senses as concrete mental entities, not as abstract entities (as Frege understood them).
} 
reference, modal status, truth value, and truth conditions) are not. Therefore, if analyticity were understood as truth in virtue of meaning alone (a fortiori, as something which demands the truth of the sentences to which it applies), analyticity will not be a sense property. ${ }^{5}$ However, it seems to Katz that analyticity should be understood as a sense property, because it seems to him that ordinary speakers' knowledge that (5) is analytic is of a piece with their knowledge that (6) is redundant.

(5) Squares are rectangles.

(6) rectangular square

For, it seems to Katz, the judgment that (5) is analytic, no less than the judgment that (6) is redundant, is the result of what competent speakers know ( $a$ priori) about expressions of their language. In particular, both judgments are based upon knowledge of a certain relationship holding between the sense of 'square' and that of 'rectangle'.

This leads Katz to define 'analyticity' not in terms of any referential properties, but in terms of a relation between senses:

(G) A sense of a simple sentence is analytic if that sense is fully contained in the sense of (any) one of its terms (12). ${ }^{6} 7$

This non-referential notion of sense, thinks Katz, puts the question whether particular sentences are analytic (and other questions about their sense properties) entirely on a footing with other simple questions in empirical domains:

Consider Donnellan's ... question whether the zoologist or the sailor is right about the sense of 'whale'. We frame a hypothesis $H 1$ on which the sense of 'whale' contains the sense of 'animal'. We also frame hypotheses $H 2, \ldots, H n$ on which the senses of the two words

\footnotetext{
${ }^{5} \mathrm{Katz}$ connects the traditional construal of analyticity (truth in virtue of meaning alone) with Frege's definition of analyticity as truth based on logical laws and definition (cf. [Frege, 1953], 92-93), and points out that it is accepted both by philosophers who give an important role to the analytic (e.g., [Carnap, 1956], 222) and those who do not (e.g., [Quine, 1953a], 21). The widespread acceptance of this understanding of analyticity leads Katz to refer to it as "the standard view" (1). But the standard view wasn't always so standard; see note 18 .

${ }^{6}$ Assuming the sense of a sentence is composed somehow from the senses of its constituent words, we might wonder how the sense of a sentence is contained in the sense of one of its words - how can the whole be contained in one of its proper parts? Remember that Katz thinks senses of (not only sentences but) words are structured. Suppose, then, that the sense of 'bachelor' is a complex structure which includes the sense unmarried man; then the sentence 'bachelors are unmarried' will be analytic with respect to $(G)$ just in case that sentence's sense involves a structural relationship between the senses bachelor and unmarried which is already part of the sense bachelor itself. In this case, the sense contribution made by the word 'unmarried' to the sense of the sentence will be redundant.

${ }^{7} \mathrm{Katz}$ warns, in footnote 2 on page 12 , that " $(\mathrm{G})$ is not intended as a definition of analyticity, but only as a presentation of the core idea," and refers to his more complete treatment in ([Katz, 1972], 171-197). However, it will suffice for present purposes to focus attention on $(\mathrm{G})$.
} 
are not so related. Assuming the hypotheses are as simple as possible, we compare the predictions they make about the sense properties and relations of sentences in which 'whale' and 'animal' appear with the judgments speakers make about the sentences. If $H 1$ makes significantly better predictions than $H 2, \ldots, H n$, we accept $H 1$ in the same spirit as we accept other scientific hypothesis. If it does not, we accept the hypothesis that makes the best predictions or continue the study (13).

Thus, modulo familiar philosophy of science worries about confirmation, evidence, etc., there is no in principle problem in deciding whether a sentence is analytic.

In effect, Katz is proposing the existence of a level of linguistic description, something we might call the sense level. Or, better, he's proposing to split the traditionally recognized semantic level into a sense level and a referential level. On this proposal, expressions have, in addition to their syntactic and phonological properties, certain sense properties and referential properties. But since sense and reference are separated on Katz's picture, we should no more expect an expression's sense properties to determine its referential properties than we should expect its syntactic properties to determine its phonological properties. Thus, for example, to say that a particular sentence is analytic is just to say that among the linguistic properties attaching to that sentence is the sense property described in (G). This hypothesis, by itself, tells us nothing about the referential properties of the sentence, and it should be verified by empirical tests against native speaker intuitions in exactly the way the hypothesis that a sentence has (say) the syntactic property of being left-embedded is tested against native speaker intuitions.

In this way, Katz hopes that his new intensionalism can provide straightforward answers to traditional worries about analyticity by locating that notion (and the other sense properties) within the realm of the internal properties investigated by linguistic theory. This is an interesting proposal; unfortunately, I shall argue, there are compelling reasons for thinking it cannot be sustained.

\section{Motivations Reconsidered}

I want to begin evaluating Katz's proposal in this section by critically examining the motivations he gives for wanting a referentially autonomous theory of sense. The motivations we've reviewed so far have consisted of (i) the claim that a referentially autonomous sense could reconcile externalist conclusions about reference with the claim that sense is in the head, and (ii) Katz's arguments that sense determines neither token- nor type-reference. Of course, motivations of type (i) will be unpersuasive if (as I shall argue in §4) Katz's referentially autonomous sense has exorbitant costs. But before we get to these challenges, I want to examine the type (ii) considerations which, according to Katz, should persuade us to abandon the Fregean thesis that sense determines reference. I 
shall argue that, first, sense does determine token-reference, and second, although Katz is right that sense does not always determine type-reference, this poses no threat to Fregean semantics.

\subsection{Sense and Token-Reference}

Katz says that token-reference is "the reference of linguistic tokens" (9). I want to show that, on this understanding, Katz's arguments against the determination of token-reference by sense are unsuccessful. For, I shall suggest, Katz's arguments will be undone if we insist on enforcing a conceptual distinction between the reference of a linguistic token and the individual whom the speaker of the token wishes to discuss.

To see how this works, let us consider the cases used by Katz to argue against the possibility that senses determine token-reference: uses of (4) where the subject NP refers to a woman drinking water, and the phenomenon of nonliteral usage. As explained in [Kripke, 1977], we may hold that that the referent of the token of the subject NP in (4) (what Kripke called the semantic-referent) is determined by its sense, even though (4) can be used in certain settings to convey information about a woman drinking water. It can do this because, Kripke argued, general and independently motivated pragmatic mechanisms make auditors aware that the semantic-referent is different from the person whom the speaker wishes to discuss (the speaker-referent), and therefore that there is some other content - content not determined by the meanings of the words in (4) - which the speaker is trying to convey. This pragmatically conveyed content may be about a woman drinking water, despite the tokenreference of the NP in (4). Crucially, on this line of explanation, even when (4) tells us about a woman drinking water, the referent of the token of its subject NP is not any woman drinking water - rather, the token refers to nothing, since nothing fits the description (or, accidentally, it might refer to someone other than the speaker's intended referent). ${ }^{8}$

A similar story works for non-literal uses as well. When Romeo uses $\left(4^{\prime}\right)$ to proclaim his love for Juliet,

$\left(4^{\prime}\right)$ Juliet is the sun.

there's no reason to think his token of the NP 'the sun' refers to anything other than the sun. Of course, what Romeo has said is not literally true, but he conveys something else - something non-literal - by his utterance, and this something likely does not involve the sun. Once again, this extra content is conveyed by the interaction of the semantic content (determined by the senses of the expressions) with general pragmatic mechanisms. But so long as we distinguish between this pragmatically conveyed content and the semantic content of (4), there's no barrier to thinking that sense determines token-reference. ${ }^{9}$

\footnotetext{
${ }^{8}$ Once again, this discussion of definite descriptions could be cast in more Russellian (i.e., quantificational) terms, but I'm following Katz in not doing so for present purposes.

${ }^{9}$ I don't think the explanations I have mounted for reconciling the cases Katz presents with
} 
Thus, the cases Katz brings up do not threaten the Fregean thesis that sense determines token-reference unless we conflate the token-reference of an expression with the individual whom the speaker of the token wishes to discuss. However, [Kripke, 1977] provided widely accepted reasons for thinking this conflation is inadvisable in cases like those under discussion. If this is right, then Katz's claims about token-reference are not damaging to the Fregean thesis that sense determines token-reference.

\subsection{Sense and Type-Reference}

Why does Katz reject the claim that sense determines type-reference? Again, we can ignore for now Katz's contention that rejecting this conclusion allows us to combine externalism about reference with internalism about senses. Aside from this, his main objection against type-reference determination has to do with the possibility of meaningful expression types that have no type-reference even though they have sense properties. He points to relative adjectives as one example of such an expression type.

Before considering relative adjectives, I want to consider another expression type whose members apparently lack type-reference although they have sense properties: indexicals and demonstratives ('I', 'here', 'now', 'this', etc.). As it happens, Fregeans have been quite explicit in recognizing these phenomena. For example, Frege says, "The same utterance containing the word 'I' in the mouths of different men will express different thoughts, of which some may be true, others false" ([Frege, 1918], 40). ${ }^{10}$ Thus, Fregeans since at least Frege have been well aware that indexical and demonstrative expressions (henceforth, demonstrative-like expressions) lack type-reference, although they have held that these expressions have senses. But this means that no reasonable Fregean would defend the thesis that the sense of every expression determines its type-reference.

What, then, should the Fregean say about demonstrative-like expressions? It would seem that a Fregean mindful of Frege's reflections on 'I' should claim that demonstrative-like expressions (i) lack type-reference, (ii) have senses, and (iii) have token-reference, which is determined jointly by their senses and certain contextual parameters. And indeed, this is the kind of story which has been pursued most ardently by contemporary semanticists working in the Fregean tradition. $^{11}$

Given all this, it is puzzling that Katz does not mention demonstrative-like expressions at all in this part of his discussion. Instead, he points to relative adjectives as a counterexample to the determination of type-reference by sense.

the thesis that sense determines type-reference are original. On the contrary, I think they are widely known and widely accepted. On this kind of approach to Donnellan-inspired cases, see [Kripke, 1977] and [Neale, 1990]. Regarding the sort of treatment of non-literal uses I have recommended, see [Davidson, 1978], [Searle, 1979], and [Cohen, 1975].

${ }^{10}$ An illuminating discussion of the troubles raised by indexicals and demonstratives within Frege's philosophy of language occurs in [Perry, 1977].

${ }^{11}$ See, for example, [Lewis, 1972] and [Kaplan, 1989]. 
But if, as we have seen, Fregeans willingly give up the claim that sense determines type-reference with regard to demonstrative-like expressions, the Fregean has a natural answer to Katz's points about relative adjectives: if she can assimilate the semantics of relative adjectives to the semantics of demonstrative-like expressions, then she can plausibly insist that the former fall within the class of recognized exceptions to the claim that sense determines type-reference. ${ }^{12}$

And indeed, this avenue of response has seemed plausible to many. For example, on a standard account (derived from [Lewis, 1972]; cf., [Klein, 1991] and ([Larson and Segal, 1995], 130ff)), relative adjectives carry an additional parameter for a contextually determined "delineation", or standard of judgment. On such an account, a relative adjective such as 'big' can be assigned a set of object-delineation pairs by a lexical axiom of the form

$\operatorname{Val}(\langle x, d\rangle$, 'big') iff $x$ is at least as big as $d$.

If we use this sort of axiom as a basis for a sense for relative adjectives, then we may conclude that such expressions (i) lack type-reference, (ii) have senses, and (iii) have token-reference, which is determined jointly by their senses and a contextual parameter - that they have exactly the features of demonstrativelike expressions noted above. Thus, because Fregeans have apparently never intended the Fregean thesis to claim that sense independently determines typereference for demonstrative-like expressions, and since standard semantic treatments of relative adjectives treat these as demonstrative-like expressions, it's hard to see how Katz's observations about relative adjectives damage the sort of Fregean thesis a Fregean would endorse. ${ }^{13}$ A genuinely Fregean Fregean thesis would have to distinguish between demonstrative-like and non-demonstrativelike expressions. It would hold of non-demonstrative-like expressions that they have both a token-reference and a type-reference, and that both are determined by sense. ${ }^{14}$ Of demonstrative-like expressions, the thesis would claim

\footnotetext{
${ }^{12}$ A second way of responding to Katz's use of relative adjectives to undermine the Fregean thesis is to provide a semantics for these expressions which preserves the thesis. One way of doing this, advocated in [Lepore and Ludwig, 1998], involves treating relative adjectives as quantifier expressions rather than referring expressions. I cannot present their account here for reasons of space.

${ }^{13} \mathrm{Katz}$ also mentions proper names as a class of expressions which have senses but no typereference: "the meaning of a proper name does not provide information about what its bearers are or which of them is the contextually unique bearer which its definiteness requires" (11). Now, I think many theorists have been convinced by externalist arguments that, if sense is in the head, then the sense of a proper name doesn't determine its reference. However, the usual conclusion drawn from this is that sense should be understood externalistically (e.g., in terms of a causal chain outside the head of the speaker); such a conclusion saves the Fregean thesis that sense determines token-reference, but only at the price of taking sense outside the head. On the other hand, it's plausible that names lack type-reference: distinct tokens of a name such as 'Jonathan Cohen' can refer to different individuals - presumably, contextual parameters serve to select one of these individuals as the referent of a given token. If this is right, then a Fregean should analyze proper names as demonstrative-like expressions as well, holding that they lack type-reference, but that their senses, together with contextual parameters, determine their token-reference. Although Katz would presumably reject this solution because of his insistence that senses are in the head, he owes us an independent argument if he wants to prevent its use in defending the Fregean thesis.

${ }^{14}$ The claim that sense determines type-reference for non-demonstrative-like expressions will
} 
that their senses (together with certain contextual parameters) determine their token-reference, but that they lack type-references. So far as I can see, Katz's arguments pose no threat whatsoever to such a genuinely Fregean Fregean thesis.

\section{Autonomous Analyticity and Truth Agnosti- cism}

I've argued that Katz's arguments against a referential theory of sense are not persuasive. Now I want to begin to consider his positive arguments for the new intensionalism by pointing out something Katz acknowledges - that his autonomous theory of sense and the analyticity it underwrites can't, by themselves, do the work traditionally required of them. As we shall see in $\S 4$, Katz is aware that his autonomous theory of sense can't stand on its own, and he proposes to take up the slack left by that theory by combining it with a theory of reference. Nonetheless, he wants to maintain that the relationship between the two theories is rather loose: "On the new intensionalism, sense mediates rather than determines reference" (9). In $\S 4.2$, I shall argue that the envisioned "mediating" relationship is in fact looser than we should allow, and therefore that sense properties are left to float free of referential properties. Therefore, to bring out the costs of the complete disassociation to which I'll argue Katz is ultimately committed, it is important to be clear about just how deficient the internal theory of sense and sense properties represented by the new intensionalism is on its own.

Suppose, then, that we accept the non-referential notion of sense given to us by (D). Suppose further that we have a general characterization of how senses are structured, individuated, and so forth, so that we understand all of the sense properties listed in (D). Finally, suppose that, on this theory, it comes out that (5) is analytic. According to $(\mathrm{G})$, this will be the case if the sense of 'squares are rectangles' is completely contained in the sense of one of its terms.

Question: will (5) be true? So far, we have no reason to suppose that it will. We have been told about a relation between senses, but senses are not squares or rectangles, so we don't yet know anything about the relationship between squares and rectangles. Notice, of course, that if sense did determine reference, we might be in a position to say something about the truth of (5): for example, if the sense of 'squares' determined the class of squares, the sense of 'rectangles' determined the class of rectangles, and the sense of 'are' determined the class containment relation, we could notice that the one class was wholly contained in the other class, and hence that the state of affairs determined by the sense of (5) in fact obtains. ${ }^{15}$ Thus, for all we have been told so far, it's entirely possible

have teeth so long as there are any such expressions; of course, this is an empirical matter, but it remains at least arguable that many expressions of the language (e.g., natural kind terms, definite descriptions, generalized quantifier expressions, etc.) are non-demonstrative-like.

${ }^{15}$ Nothing of interest here hangs on the particulars of the ontology or the semantics. All that matters is that you can't get this kind of explanation going unless you connect senses 
that analytic sentences are false. ${ }^{16}$ For similar reasons, what we know so far leaves it open that synonymous sentences could differ in truth value and that antonymous sentences could coincide in truth value. ${ }^{17}$

The same moral applies to questions about modal status. If analyticity is defined by $(\mathrm{G})$, then knowing that (5) is analytic is irrelevant to deciding whether (5) is necessary or contingent. This is because the supposition that the sense of (5) is contained in the sense of one of its component terms tells us nothing about the properties, relations, or individuals at any worlds. ${ }^{18}$

Indeed, this should be completely unsurprising. As we have noted, Katz's notion of sense provides a level of linguistic description at which the properties assigned to expressions are completely independent of their referential properties. Viewed in this light, it should be no less surprising to be told that analytic sentences are all true than it would to be told that all sentences with a certain phonological property (say, that of starting with an aspirated consonant) are all

with the world, which is just what (D) precludes.

${ }^{16}$ This worry would not be so pressing if we had not followed Katz in restricting attention to only sentences free of demonstrative-like expressions. For, as argued persuasively in [Kaplan, 1989], we should allow that sentences containing indexical expressions (e.g., 'I am here now', 'I exist') can be analytic despite being contingent or even false ([Kaplan, 1989], 540, 547-549). However, on Kaplan's construal, non-metalinguistic analytic sentences containing only non-indexical, non-demonstrative expressions must be true and necessary. In contrast, Katz is considering only (non-metalinguistic) sentences entirely free of demonstrative-like expressions, and leaves it open (from what has been said so far) that these can be analytic and nonetheless false or contingent. My complaint is that an acceptable theory of analyticity should not leave this possibility open.

Henceforth, I shall restrict attention to non-metalinguistic sentences free of demonstrativelike expressions, and shall omit these qualifiers.

${ }^{17}$ Interestingly, something like this complaint was urged against the theory of analyticity in [Katz, 1966] by Leonard Linsky, who writes that "Katz's semantics gives no account whatever of the notion of truth," and concludes for this reason that, "there is no way within his explication of analyticity to show that analytic sentences are true and contradictory ones false" ([Linsky, 1972], 481). We shall see in $\S 4.1$ that Katz has an answer to this demand, but we shall argue in $\S \S 4.2-4.3$ that this answer fails, so that Linsky's complaint remains as pressing as ever.

18 Katz's strategy has precedent in Carnap's purely formal definitions of synonymy, analyticity, and the like in [Carnap, 1937]. That these notions are purely formal (what Carnap called syntactic, and Katz would call referentially autonomous) is urged by Quine in his 1934 lectures on Carnap's system ([Quine, 1990], esp. 93ff). Therefore, the objection mounted against Katz in the main text is applicable to these early views of Carnap as well: viz., unless these formal notions are brought to bear on the world somehow, we'll have no guarantee that analytic sentences are true, that synonymous sentences share truth-values, etc.

In fact, Carnap was eventually persuaded of the need to introduce non-formal (referential) notions in understanding analyticity and the the like in his later works because of precisely the kinds of concerns we are pressing against Katz: while Carnap's syntactic notions relate complex sentences to an observational basis of protocol sentences, there is no purely formal way to explain how circumstances in the world might prompt an observer to state a given protocol sentence, so analyticity and its ilk remain frictionless wheels with no grip on the world. As documented in ([Romanos, 1983], 130-138) and reflected in the epigram from [Carnap, 1963] at the beginning of the present essay, Carnap eagerly adopted the new semantic (referential) apparatus to avoid these difficulties soon after Tarski's work showed how he could do so without compromising his anti-metaphysical leanings. In light of this history, it is ironic to find [Katz, 1997] criticizing [Carnap, 1956] (and [Quine, 1953b]) for ignoring the possibility of handling analyticity in a referentially autonomous way. 
true.

Thus, because the notion of analyticity adumbrated in $(\mathrm{G})$ is divorced from reference, we have, so far, no way of knowing that sentences which are analytic in this sense are true or necessary. Of course, it would be unsatisfactory if analyticity were left in this state; we would be justified in objecting that an analyticity applying to false sentences fails to satisfy the traditional demands made of that notion. Katz knows this, and therefore wants to demonstrate that analytic sentences must be true and (weakly) necessary. To do this, he proposes a theory of reference to go along with his theory of sense, and then argues that the two theories can be combined in such a way that analyticity will meet the traditional requirements without falling victim to the objections pressed against the coherence of more standard formulations. This will be the focus of $\S 4$.

\section{Sense and Reference Reconciled?}

We've seen that, although Katz wants to defend a referentially autonomous theory of sense (and sense properties), he needs to supplement this with a theory of reference (and referential properties), and then connect the theories appropriately if he is to satisfy the usual demands made of notions such as analyticity. In $\S \S 4.1-4.2$ I shall set out and then evaluate the theory of reference he offers. In $§ 4.3$, I shall consider whether the two theories can be combined in the way Katz thinks they can.

\subsection{Katz's Theory of Reference}

Katz wants to explain how the type-reference of natural kind terms (parade cases for his externalist opponents) is determined. He supposes, then, that "the best hypothesis about the sense of 'aluminum' is that it is metal of a natural kind whose normal members are light in weight, with a bluish sliver-white color, durable, and rustless." He further supposes that "molybdenum is a metal of a natural kind whose normal members are light in weight, with a bluish silver-white color, durable, and rustless" (16). On these assumptions, Katz points out, it is left open whether molybdenum falls in the type-reference of 'aluminum'. However, he allows that 'aluminum' and 'molybdenum' are plausibly non-synonymous. He wants to show how the new intensionalism can mark these expressions as non-synonymous (as differing in sense) without sacrificing its internalism.

He explains that there are three ways in which the senses under consideration can differ:

$\left(\mathbf{H}^{*}\right)$ The senses of 'aluminum' and 'molybdenum' are different, but not opposed.

$\left(\mathbf{H}^{* *}\right)$ The senses of 'aluminum' and 'molybdenum' are opposed, and the sense components which express the opposition also conceptually characterize its nature. 
$\left(\mathbf{H}^{* * *}\right)$ The senses of 'aluminum' and 'molybdenum' are opposed, but the sense components which express the opposition provide no conceptual characterization of its nature. They simply mark the opposition (17).

Now, if $\left(\mathrm{H}^{*}\right)$ or $\left(\mathrm{H}^{* *}\right)$ obtains, then Katz thinks it will be unproblematic to assign type-references to the expressions 'aluminum' and 'molybdenum' in the right way: "if natural kind terms have a sense of the form $\left(\mathrm{H}^{*}\right)$ or $\left(\mathrm{H}^{* *}\right)$, a theory of reference can employ (E) for assigning type-reference to such terms" (18). More complicated, he thinks, are cases where the senses of the terms are of the form $\left(\mathrm{H}^{* * *}\right)$. Here, the difficulty is that the senses do not supply sufficient information to pick out type-references in a sufficiently fine-grained way. Consequently, if $\left(\mathrm{H}^{* * *}\right)$ holds, then a theory of reference employing $(\mathrm{E})$ would restrict the sentence (8) to talking about metals of a natural kind whose normal members are light in weight, with a bluish silver-white color, durable, and rustless, i.e., either aluminum or molybdenum.

(8) Aluminum is a more abundant metal than molybdenum.

Thus, (8) would express the statement that aluminum and molybdenum is more abundant than aluminum and molybdenum.

Katz recognizes that the information needed to distinguish the references of the two natural kind terms is, as Putnam pointed out, scientific knowledge of the essences in question. Katz sees this (synthetic) information as supplying a "real definition" derived not from any aspect of the grammatical structure of the expression (as are senses), but from "scientific theorizing (or conventional lore)". ${ }^{19}$ Thus, the principle for fixing the reference of expressions whose sense is of the form $\left(\mathrm{H}^{* * *}\right)$ is

$\left(\mathbf{E}^{*}\right)$ The type reference of a term having a sense of the form $\left(\mathrm{H}^{* * *}\right)$ are the thing(s) falling under both the sense and the real definition of the term (19).

On Katz's view, then, if a speaker's senses of 'aluminum' and 'molybdenum' stand in the relation given by $\left(\mathrm{H}^{* * *}\right)$, her sense competence will inform her that

\footnotetext{
${ }^{19}$ The contrast Katz is playing on here makes me a little wary, and suggests to me that I may be genuinely confused about the views under discussion. For one thing, I would have thought that while scientific specifications about the reference of a term are often poor predictors of speaker judgments about synonymy, ambiguity, and the like, conventional lore would be quite useful in framing hypotheses about Katz's sense-structures; therefore, a notion of real definitions built from conventional lore threatens to collapse onto sense (thereby obliterating Katz's analytic/synthetic distinction). On the other hand, if conventional lore is part of the real definition of a kind term, then real definitions will inherit all the errors embedded in erroneous folk conceptions (e.g., that whales are fish, that fool's gold is gold, etc.). But Katz can't allow this, since he thinks real definitions will correctly pick out the extensions of kind terms when senses fail (see below).

I don't know what Katz would say about this, but one way to block these concerns would be to treat real definitions of kind terms as if they are just scientific specifications, and give no role in determining real definitions to conventional lore. This strategy makes room for a difference between sense and real definition, and would allow real definitions to pick out extensions correctly when senses fail. For these reasons, I shall adopt this reading.
} 
these senses are, in Katz's terminology, incomplete descriptions, and hence that extra-linguistic knowledge must be enlisted to determine the reference for the terms.

Thus, Katz offers a theory of reference built from the principles (E) and $\left(\mathrm{E}^{*}\right)$. In $\S 4.2 \mathrm{I}$ want to argue that this theory is unsuccessful.

\subsection{Reference Refused}

It seems to me that, for reasons discussed in [Kripke, 1980], the theory of reference Katz has described will assign the wrong reference to many expressions in the language. Kripke argued that internal senses could fail to determine a referent in any of three ways: they could underdescribe a kind, they could describe the wrong kind, or they could describe no kind at all. Katz claims that his use of the principle $\left(\mathrm{E}^{*}\right)$ assigns type-reference to natural kind terms whose internal senses underdetermine their references. I shall claim that this strategy fails, except when, coincidentally, sense drops out and reference does all the work (thereby sapping the force of Katz's internalism). But even if this proposal succeeded in explaining reference in cases where sense underdetermines reference, it says nothing about the other kinds of cases Kripke raised. I shall argue that neither Katz's theory nor any modification consonant with his internalism can succeed in these other sorts of cases.

First, I want to show that, even for cases where sense underdetermines reference, $\left(E^{*}\right)$ succeeds only when the real definition does all the work. Suppose, then, that $\left(\mathrm{E}^{*}\right)$ gives the correct account of how the reference of a term is determined when $\left(\mathrm{H}^{* * *}\right)$ obtains. Call the class of things falling under the sense of the term $S$ and the class of things falling under the real definition of the term $R$. ( $\left(\mathrm{E}^{*}\right)$ says that the extension of the term is $(S \cap R)$. We know that $S \neq R$, or else we would have said that the reference of the term is determined by (E) rather than $\left(\mathrm{E}^{*}\right)$. Therefore, $(S \cap R) \subseteq R$. If $(S \cap R)=R$, then the force of $\left(\mathrm{E}^{*}\right)$ is that real definitions, rather than senses, determine reference. On the other hand, suppose $(S \cap R) \subset R$ - that the intersection is properly contained in $R$. Assume that $(S \cap R)$ is non-empty. ${ }^{20}$ If $(S \cap R) \subset R$, then, to take Katz's example, the extension of 'aluminum' would exclude objects which the ultimate scientific theory of metals classifies as aluminum. This seems unacceptable. Thus, $\left(\mathrm{E}^{*}\right)$ works only when it collapses onto the principle that the extension of a term is fixed by its (external) real definition.

However, although this argument shows that $\left(\mathrm{E}^{*}\right)$ either fails or undermines Katz's internalism with respect to the underdetermination cases for which it was designed, the situation is even worse, because there are further problem cases for Katz's theory of reference. Consider the following sentence:

(9) Whales eat plankton.

\footnotetext{
${ }^{20}$ If $(S \cap R)$ is empty, then Katz's theory would have the consequence that the term would fail to refer. But this will be correct only where $R$ itself is empty (no matter what $S$ is). This is just to say that if $(S \cap R)$ is empty, Katz's theory fails to assign the correct reference except when, coincidentally, it collapses onto the externalist theory that real definitions determine reference.
} 
It seems entirely plausible that, at least at some time, the best evidence might support the hypothesis that the sense of 'whales' includes fish. ${ }^{21}$ But since whales are not fish, if the reference of the term is determined by (E), then (9) will be about some sort of fish (perhaps a very large sort of fish), rather than whales; surely this is not correct. On the other hand, if the reference of the term is determined by $\left(\mathrm{E}^{*}\right)$, then (9) will be about whatever falls under the sense and the real definition, or whatever is a fish and a whale. But nothing is a fish and a whale, so we'd have to conclude that if reference is determined by $\left(\mathrm{E}^{*}\right)$, then the term fails to refer; again, this seems implausible. ${ }^{22}$ Thus, if the sense of 'whale' is revealed as including fish, then the theory of reference Katz has sketched either assigns the wrong reference or no reference at all to the term.

Similarly, the best evidence from ordinary speakers might support the hypothesis that the sense of 'whales' is large mammalian fish. I am given to understand that nothing is a large mammalian fish, because nothing which is a mammal can be a fish. Thus, there would be nothing which could fall under the sense of 'whales', so whether the reference of the term in (9) is determined by $(\mathrm{E})$ or $\left(\mathrm{E}^{*}\right)$, the term would fail to refer. Once again, this is implausible.

Thus, as Kripke pointed out in [Kripke, 1980], if senses are understood as what typical speakers know about the things which fall under terms, sense can not only underdetermine extension, but can also determine the wrong extension

\footnotetext{
${ }^{21}$ For example, Melville's Ishmael insists that a whale is a fish despite his familiarity with scientific claims to the contrary:

...in some quarters it still remains a moot point whether a whale be a fish. In his System of Nature, A.D. 1776, Linnaeus declares, "I hereby separate the whales from the fish." But of my own knowledge, I know that down to the year 1850 , sharks and shad, alewives and herring, against Linnaeus's express edict, were still found dividing the possession of the same seas with the Leviathan... Be it known that, waiving all argument, I take the good old fashioned ground that the whale is a fish, and call upon holy Jonah to back me (Moby Dick, Chapter $32)$.
}

Moreover, we can call upon holy Jonah to back our contention as well: if Ishmael's opinion that the whale is a fish had not been fairly widespread at some time, it is hard to see how the Hebrew expression 'dag gadol' (great fish) could have been so widely mistranslated as 'whale'.

${ }^{22}$ Objection: This argument depends on supposing that when people gave the sense of 'whale' partly in terms of the sense of 'fish', the latter sense is the same as the sense attached to 'fish' by present day zoologists (or at least that its real definition is what the real definition of 'fish' as used by zoologists nowadays is). However, as an anonymous referee points out, this supposition is dubious: it's plausible that the sense of 'fish' has undergone a change from something like aquatic animal with fins and a tail to something much more specific. If there has been such a change, then the counterexample breaks down due to an equivocation on fish.

Reply: Perhaps there has been such a change; if so, consider a different example taken from Katz's discussion. Katz allows that Putnam was right in holding that 'cat' might have (without requiring any change in its sense) picked out robots rather than feline animals (14). But since he also maintains that 'cats are animals' is analytic (14), he must think that the sense of 'cats' contains the sense of 'animal', and that this would be so even in a world where 'cat' picked out robots. Therefore, if the reference of 'cat' in such a world were determined by $\left(\mathrm{E}^{*}\right)$, then the term would refer to things which are both felines and robots; since there are no such things in that world (we may suppose that there are no felines there, but only robots), this would mean that 'cat' in the sentence 'cats are animals' would fail to refer. 
or no extension. If, as Katz tells us, the sense of a term is determined by the empirical evidence given by speaker judgments about redundancy, ambiguity, and the like, there seems every reason to think such difficulties will arise. Therefore, it would appear that Katz's theory of reference involving (E) and $\left(\mathrm{E}^{*}\right)$ will make incorrect predictions in the kinds of cases we have imagined.

So where do we stand at this point? Recall that Katz offered an internal, referentially autonomous theory of sense, and used this theory of sense to ground a referentially autonomous notion of analyticity. But, as we argued in $\S 3$, to prevent this notion of analyticity from losing touch with the desirable properties of analytic sentences, he needs to show that sense properties connect with referential properties in a fairly intimate way, notwithstanding his claims about the referential autonomy of sense properties. However, as we've seen in this section, since Katz's senses are constituted by speakers' widespread beliefs which can be wrong - they cannot determine reference. Thus, it seems that only real definitions can correctly determine reference. However, Katz can only use this conclusion to connect sense and reference if he is prepared to identify senses with real definitions. Since this would mean taking sense back out of the head, I don't see how Katz could accept this possibility.

\subsection{Putting Humpty Together Again}

Remember that Katz needs to join his theory of reference with his theory of sense in order to prevent the possibility that sentences could be analytic but false (a possibility which would undercut almost all interest in the notion of analyticity). Therefore, he gives a proof that the sense property of analyticity is linked to its "referential correlate" notion of weak necessity. He begins with the following terminological claims:

(J) A possible world $w$ is a satisfier world for a proposition $p$ just in case, for each term $t$ in $p$, there are objects in $w$ which fall under $t$.

(K) A proposition $p$ is a weakly necessary truth just in case (i) $p$ is a logical truth or (ii) there are possible worlds which are satisfier worlds for $p$ and $p$ is true in every satisfier world for $p(24)$.

Under these definitions, Katz wants to prove that analytic sentences will be not only true but will express weakly necessary propositions. ${ }^{23}$ His argument is this:

Consider an arbitrary sentence ... with a sense $p$ that is analytic with respect to $(\mathrm{G})$. Given $p$ is analytic with respect to $(\mathrm{G})$, it contains a term $t$ having the entire sense content of $p$. Hence the conditions for $t$ having a non-empty extension include the truth conditions of $p$. In determining weakly necessary truth, the worlds with which we are concerned are all and only the satisfier worlds for $p$. Since $t$ has

\footnotetext{
${ }^{23}$ In conversation, Katz has referred to this argument as a "soundness proof." I take it that this terminology is intended to bring to mind analogous results about the correlations between syntactic and semantic properties of expressions of formal languages.
} 
a non-empty extension in all of those worlds, $p$ is true in all of its satisfier worlds, and, by $(\mathrm{K}), p$ is a weakly necessary truth $(24-25)$.

Unfortunately, there seem to be straightforward counterexamples to the conclusion of this argument. To see this, consider Katz's sentence (2):

(2) Cats are animals.

Consider this sentence with respect to a world $w$ like ours in every respect except that Putnam's story about robot cats is true in $w$. People in $w$ speak the language Shmenglish, which is just like English except that its term 'cat' refers to the robot cats of $w$, rather than the felines of our world (which, we may suppose, are absent in $w$ ). Suppose further that the senses of 'cats' and of 'cats are animals' are in Shmenglish just what they are in English (despite the difference in the real definition of 'cat') and that 'animal' has the same real definition in English and Shmenglish. Katz allows that all this is possible, and that (2) may nonetheless be analytic in English (14). But if (2) is analytic in English with respect to $(\mathrm{G})$, then (2) is analytic in Shmenglish with respect to $(\mathrm{G})$, since the sense properties of 'cat' and (2) are held constant between the two languages. On the other hand, (2) is necessarily false in Shmenglish, given the real definition of 'cats'. However, since it is necessarily false, it cannot be weakly necessary, notwithstanding its analyticity. Thus Katz's proof fails.

Indeed, from what we've said already, it should be obvious that what has gone wrong in the proof concerns its inference from the presence of a certain sense property to the presence of a certain referential property (a property concerning truth conditions). Suppose, with Katz, that (2) is analytic with respect to $(\mathrm{G})$ in virtue of having a term $t$ (I take it this would be 'cats') whose sense contains the entire sense content of the sentence. ${ }^{24}$ As we argued in $\S 4.2$, given this relationship between senses, we have no idea how cats are related to animals, because we have no idea whether what the sense features of 'cats' would require of something is what is required for falling in the extension of the term. The truth conditions of (2), of course, involve the correct specification of the real definition 'cat' — i.e., the correct scientific account of what it is to be a cat. But we've seen that there's every reason to think sense features and the features of real definitions can come apart wildly, because (not to put too fine a point on it) people are often vastly wrong in what they believe about cats. $^{25}$ And when people happen to be right in what they believe about cats, this is not the result of careful attention to the semantics of their languages, but the result of studying and observing members of that kind. Thus, given what Katz tells us senses are, the most we can conclude from the fact that the

\footnotetext{
${ }^{24}$ Perhaps the sense of 'cats' is have whiskers, have a tail, eat, reproduce sexually, while the sense of 'are animals' is eat, reproduce sexually, so that the sense of (2) is contained in the sense of 'cats'.

${ }^{25}$ Of course, the beliefs about cats that matter for present purposes are the kinds of conventional beliefs that empirical research reveals to be part of sense-structure of 'cats', and it may be that this is a very limited subset of any person's beliefs about cats. But the point still applies: there's every reason for thinking that even our limited subsets of conventional beliefs contain falsehoods.
} 
sense of (2) is contained in the sense of 'cats' is that whatever are picked out by common conceptions of the extension of 'cats' are commonly held to be animals. It certainly does not follow from this that actual cats are in fact animals, in this or any other world.

It seems, then, that Katz's attempted rapprochement fails: if analyticity is construed as an internal relation among senses, then analytic sentences can be contingent or even false. But if Katz's theory provides a notion of analyticity which will apply to contingent and false sentences, then it seems fair to complain that this theory does not speak to the longstanding philosophical interest in the analytic.

\section{Conclusion}

I think that Katz is right that "the standard view" of analyticity is extremely widespread, and that it would be of great significance to philosophy to find a way of replacing it. However, I don't think that Katz's anti-Fregean alternative can succeed. Indeed, although I've focused on Katz's proposal, I think the problems I've tried to bring out give quite general reasons for thinking that no purely non-referential (internal) theory of analyticity can succeed. Thus, we are left with the following dilemma.

Either sense can be understood internally (as Katz advocates) or externally. If it is understood internally, then it can be used to define a coherent internal notion of necessity (i.e., conceptual or analytic necessity), but sense will fail to determine reference. Although this might initially seem an acceptable cost (remember Katz's claim that sense "mediates", but does not determine reference), it has the unpalatable consequence that it allows for false analytic sentences. Alternatively, if we understand sense externally, then we can hold that sense determines reference, and consequently we can prevent the possibility of false analytic sentences. However, adopting this second horn of the dilemma means relinquishing our internal notion of sense, and therefore giving up the tidy account of analyticity Katz offers.

Thus, it looks as if we are being offered a choice between accepting Katz's internal notion of analyticity, which we know to be wrong, or admitting that we lack a plausible theory of analyticity. Given these choices, I think we have little option but to reject Katz's proposal. ${ }^{26}$

\section{References}

[Block, 1986] Block, N. (1986). Advertisement for a semantics for psychology. Midwest Studies in Philosophy, 10. Reprinted in [Stich and Warfield, 1994], $81-141$.

\footnotetext{
${ }^{26}$ Thanks to Jerry Fodor, Ernie LePore, Mark Moyer, Philip Robbins, and an anonymous referee for helpful comments on earlier drafts.
} 
[Burge, 1979] Burge, T. (1979). Individualism and the mental. In French, P., Euhling, T., and Wettstein, H., editors, Studies in Epistemology, volume 4 of Midwest Studies in Philosophy. University of Minnesota Press, Minneapolis.

[Carey, 1991] Carey, S. (1991). Knowledge, acquisition: Enrichment or conceptual change? In Carey, S. and Gelman, R., editors, The Epigenesis of Mind. Lawrence Erlbaum, Hillsdale, New Jersey.

[Carnap, 1937] Carnap, R. (1937). The Logical Syntax of Language. Harcourt Brace, New York. German version published in 1934.

[Carnap, 1956] Carnap, R. (1956). Meaning and Necessity. University of Chicago Press, Chicago.

[Carnap, 1963] Carnap, R. (1963). Intellectual autobiography. In Schilpp, P. A., editor, The Philosophy of Rudolf Carnap, volume 11 of The Library of Living Philosophers Series, pages 1-84. Open Court Press, Lasalle, Illinois.

[Cohen, 1975] Cohen, T. (1975). Figurative speech and figurative acts. The Journal of Philosophy, 72(19):669-684.

[Davidson, 1978] Davidson, D. (1978). What metaphors mean. Critical Inquiry, 5(1):31-47. Reprinted in [Davidson, 1984].

[Davidson, 1984] Davidson, D. (1984). Inquiries into Truth and Interpretation. Clarendon Press, Oxford.

[Donnellan, 1966] Donnellan, K. (1966). Reference and definite descriptions. The Philosophical Review, 75:281-304. Reprinted in [Martinich, 1990].

[Frege, 1918] Frege, G. (1918). Thoughts. In McGuinness, B., editor, Gottlob Frege: Collected Papers on Mathematics, Logic, and Philosophy. Basil Blackwell, Oxford, England.

[Frege, 1953] Frege, G. (1953). The Foundations of Arithmetic: A logicomathematical enquiry into the concept of number. Basil Blackwell, Oxford. Translated by J. L. Austin. Originally published in 1884 .

[Gopnik, 1988] Gopnik, A. (1988). Conceptual and semantic development as theory change. Mind and Language, 3:197-216.

[Harman, 1982] Harman, G. (1982). Conceptual role semantics. Notre Dame Journal of Formal Logic, 23:242-256.

[Kaplan, 1989] Kaplan, D. (1989). Demonstratives: An essay on the semantics, logic, metaphysics, and epistemology of demonstratives and other indexicals. In Almog, J., Perry, J., and Wettstein, H., editors, Themes From Kaplan, chapter 17, pages 481-563. Oxford University Press, New York. Originally circulated as a mimeograph from the Department of Philosophy, UCLA. 
[Katz, 1966] Katz, J. J. (1966). The Philosophy of Language. Harper and Row, New York.

[Katz, 1972] Katz, J. J. (1972). Semantic Theory. Harper and Row, New York.

[Katz, 1997] Katz, J. J. (1997). Analyticity, necessity, and the epistemology of semantics. Philosophy and Phenomenological Research, 57(1):1-28.

[Katz and Fodor, 1963] Katz, J. J. and Fodor, J. A. (1963). The structure of a semantic theory. Language, 39:170-210.

[Keil, 1987] Keil, F. (1987). Conceptual development and category structure. In Neisser, U., editor, Concepts and Conceptual Structure. Cambridge University Press, Cambridge.

[Klein, 1991] Klein, E. (1991). Comparitives. In von Stechow, A. and Wunderlich, D., editors, Semantics: An International Handbook of Contemporary Research, pages 673-691. Walter de Gruyter, Berlin.

[Kripke, 1977] Kripke, S. (1977). Speaker reference and semantic reference. In French, P. A., Uehling, T. E., and Wettstein, H. K., editors, Contemporary Perspectives in the Philosophy of Language, pages 6-27. University of Minnesota Press, Minneapolis. Reprinted in [Martinich, 1990].

[Kripke, 1980] Kripke, S. (1980). Naming and Necessity. Harvard University Press, Cambridge, Massachusetts.

[Larson and Segal, 1995] Larson, R. and Segal, G. (1995). Knowledge of Meaning: An Introduction to Semantic Theory. MIT Press, Cambridge, Massachusetts.

[Lepore and Ludwig, 1998] Lepore, E. and Ludwig, K. (1998). Conceptions of logical form. Ms. Rutgers University and University of Florida.

[Lewis, 1972] Lewis, D. (1972). General semantics. In Davidson, D. and Harman, G., editors, Semantics of Natural Language, pages 169-218. Reidel, Dordrecht.

[Linsky, 1972] Linsky, L. (1972). Analytic/synthetic and semantic theory. In Davidson, D. and Harman, G., editors, Semantics of Natural Language, pages 473-482. Reidel, Dordrecht.

[Martinich, 1990] Martinich, A. P. (1990). The Philosophy of Language, second edition. Oxford University Press, New York.

[Neale, 1990] Neale, S. (1990). Descriptions. MIT Press, Cambridge, Massachusetts.

[Partee, 1995] Partee, B. (1995). Lexical semantics and compositionality. In Gleitman, L. and Lieberman, M., editors, Invitation to Cognitive Science, Second Edition, volume 1. MIT Press, Cambridge, Massachusetts. 
[Perry, 1977] Perry, J. (1977). Frege on demonstratives. The Philosophical Review, 86:474-97.

[Putnam, 1975] Putnam, H. (1975). The meaning of 'meaning' . In Mind, Language, and Reality: Collected Papers, Volume 2, pages 215-271. Cambridge University Press, New York.

[Quine, 1953a] Quine, W. V. O. (1953a). From a Logical Point of View: 9 Logico-Philosophical Essays. Harper and Row, New York.

[Quine, 1953b] Quine, W. V. O. (1953b). Two dogmas of empiricism. In Quine, W. V. O., editor, From a Logical Point of View. Harper and Row, New York. Originally in the Philosophical Review, 1951.

[Quine, 1990] Quine, W. V. O. (1990). Lectures on Carnap. In Creath, R., editor, Dear Carnap, Dear Van: The Quine-Carnap Correspondence and Related Work. University of California Press, Berkeley. Lectures delivered in 1934.

[Romanos, 1983] Romanos, G. D. (1983). Quine and Analytic Philosophy: The Language of Language. MIT Press, Cambridge, Massachusetts.

[Rosch, 1978] Rosch, E. (1978). Principles of categorization. In Rosch, E. and Lloyd, B. B., editors, Cognition and Categorization, pages 27-48. Lawrence Erlbaum, Hillsdale, New Jersey.

[Searle, 1979] Searle, J. (1979). Metaphor. In Ortony, A., editor, Metaphor and Thought, pages 92-123. Cambridge University Press, Cambridge.

[Smith and Medin, 1981] Smith, E. E. and Medin, D. L. (1981). Categories and Concepts. Harvard University Press, Cambridge, Massachusetts.

[Stich and Warfield, 1994] Stich, S. P. and Warfield, T. A. (1994). Mental Representation: A Reader. Basil Blackwell, Oxford.

[Wittgenstein, 1953] Wittgenstein, L. (1953). Philosophical Investigations. Macmillan, New York. Translated by G. E. M. Anscombe. 